\title{
CONVERSION OF LIGNOCELLULOSIC BIOMASS IN BIOBUTANOL BY A NOVEL THERMAL PROCESS
}

\author{
MARICELLY MARTINEZ ${ }^{1,2}$, XAVIER DURET ${ }^{1}$, DOAN PHAM MINH ${ }^{2}$, ANGE NZIHOU $^{2} \&$ \\ JEAN-MICHEL LAVOIE ${ }^{2}$ \\ ${ }^{1}$ Department of Chemical and Biotechnological Engineering, Université de Sherbrooke, Biomass technology \\ laboratory, Canada. \\ ${ }^{2}$ Université de Toulouse, IMT Mines Albi, UMR CNRS 5302, Centre RAPSODEE, France.
}

\begin{abstract}
This work aims at demonstrating the possibility of producing 2-butanol from lignocellulosic biomass through a new thermochemical approach. The production of biobutanol was carried out using different lignocellulosic feedstock through a 3-step process: first the whole lignocellulosic biomass is hydrolyzed under acid catalyst to produce levulinates, then the levulinates go through decarboxylation to produce 2-butanone which is, in a final step, reduced to produce of 2-butanol. The experimental conditions for the first two steps of the process were optimized using the response surface methodology (RSM). The latter could represent an opportunity for the production of economical second-generation butanol without having to go through the classical pathway requiring the production of sugar prior to microbial conversion.

Keywords: homogeneous and heterogeneous catalyst, Lignocellulosic biomass, levulinates, platform chemicals, pyrolysis, 2-butanol, biofuel.
\end{abstract}

\section{INTRODUCTION}

The global dependency towards petroleum-based fuels has a significant impact on the global production of carbon dioxide, which is often related to climate change. For decades, scientists, politicians and citizens in many countries have been working to explore the possibility or relying on renewable sources of energy including the production of alternative fuels and chemicals from renewable carbon sources such as biomass [1].

The most common alternative fuels actually under investigation and/or production includes bioethanol, biodiesel, hydrogen, liquefied petroleum gas, biogas, etc. Recently, ethanol has been widely used as an additive to gasoline in spark ignition engines as well as in diesel engines [2]. This alcohol has a high octane number, improves anti-knock characteristics and, depending on how it is made, can significantly reduce greenhouse gas emissions [3].

In recent years, biobutanol has also gained significant attention in the biofuel community since some of its physical and chemical properties (as fuel) are superior to ethanol, such as its energy value and octane numbers. Butanol can substitute ethanol in gasoline with an overall positive impact on the fuel's energy value. The current world demand for butanol exceeds 1.2 billion gallons per year, a market valued at more than $\$ 6$ billion USD, growing at a rate of $3 \%$ per year, and expected to reach $\$ 9.9$ billion USD by 2020 [4].

At this point, the production of 2-butanol is essentially made by chemical synthesis. The alternative production process involves the catalytic condensation of ethanol to produce butanol following hydration of n-butene [5]. This process uses methods that are generally expensive and not environmentally friendly. 2-butanol can also be obtained from acetolactate and acetoin using certain strains of Lactobacillus [6]. Unfortunately, the use of this process has been diminished due to low yields, expensive recovery phase and high costs of fermentation substrates. 


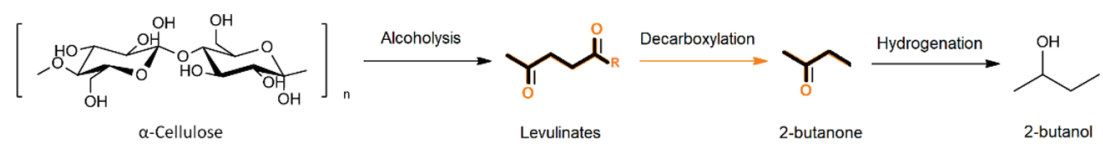

Figure 1: General mechanism of 2-butanol production reactions.

In order to increase the impact of biobutanol as fuel substitute, the raw material must be widely available and obtained at low cost. Therefore, processes involving the use of cheap biomass (such as lignocellulosic biomass) could increase economic efficiency. In Canada, the lumbering industry produces large volumes of residues (such as bark, sawdust, tree tops, etc.) The price of lignocellulosic residues from the forest sector ranges below $\$ 5$ per ton for bark and starts at $\$ 40$ per ton for wood chips. Residual forest biomass hence represents a good opportunity to produce platform molecules and fuel additives that could increase the economic viability of these processes [7].

This work aims to demonstrate the possibility of producing 2-butanol from lignocellulosic biomass through a novel thermochemical route. The production of biobutanol will be carried out using lignocellulosic cellulose in three steps of which the first involves the hydrolysis of the cellulosic part of lignocellulosic biomass for the production of levulinates. Levulinates are then decarboxylated to produce 2-butanone, which is then reduced to obtain 2-butanol (Fig. 1). Such approach could be a possible way to reduce the conventional problems of 2-butanol production while contributing to the implementation of low-cost production process for a potential second-generation biofuel.

\section{BIOBUTANOL PROCESSES}

2-butanol or sec-butanol $\left(\mathrm{C}_{4} \mathrm{H}_{9} \mathrm{OH}\right)$ is a straight chain alcohol, where the hydroxy group is bonded on one of the two secondary carbons. This chemical is used as intermediate substance in the chemical synthesis of several products and as solvent for a variety of chemicals in industry such as for the production of textile, pharmaceutical as well as in the energy industry.

Compared to ethanol, 2-butanol has less affinity for water as well as being less corrosive, less volatile, and less flammable. $\mathrm{BuOH}$ is more soluble in diesel and gasoline (without the use of co-solvents). In addition, the low vapor pressure of butanol allows its use in existing gasoline transmission pipelines without significant adaptation. Another advantage of butanol over ethanol is that butanol is less anhydrous which reduces the risk of water contamination by fuel [8].

The volume energy content of butanol $(29.2 \mathrm{MJ} / \mathrm{L})$ is $30 \%$ higher than that of ethanol $(21.2 \mathrm{MJ} / \mathrm{L})$ and $10 \%$ lower than that of gasoline (32.5 MJ/L). On the other hand, the butanol research octane number is significantly closer to gasoline, which to a certain point indicates some similar fuel properties. A comparison of the properties of butanol with those of ethanol and gasoline is presented in Table 1.

Traditionally, 2-butanol was produced by hydrating n-butene with water in the presence of sulfuric acid as a catalyst [9]. However, this process has been eliminated due to some serious disadvantages such as corrosion, which often induced excessive investment in CAPEX. For the hydration part of the process, many homogeneous and heterogeneous catalysts have been reported to be efficient over the years such as heteropolyacids, resins as well as molecular sieves. Although significant progress has been made, many disadvantages remain regarding this approach, such as its high-energy consumption, the short catalyst life 
Table 1: Properties for combustion of 2-butanol as compared to ethanol and gasoline [10] [11].

\begin{tabular}{lccc}
\hline Property & Butanol & Ethanol & Gasoline \\
\hline Chemical formula & $\mathrm{C}_{4} \mathrm{H}_{9} \mathrm{OH}$ & $\mathrm{C}_{2} \mathrm{H}_{5} \mathrm{OH}$ & $\mathrm{H}, \mathrm{C}_{4}-\mathrm{C}_{12}$ \\
Calorific value (MJ/L) & 29.2 & 21.2 & 29.2 \\
Research octane number & 101 & 129 & $91-99$ \\
Motor octane number & 32 & 102 & $81-89$ \\
\hline
\end{tabular}

and the overall low n-butene conversion $(<10 \%)$. Therefore, the development of an efficient, stable and environmentally friendly process for the production of 2-butanol is relevant in the actual context.

The process that will be reviewed in this manuscript involves three basic steps to produce 2-butanol from a whole array of lignocellulosic feedstock using a novel thermochemical approach:

Step 1: Levulinates production from lignocellulosic biomass.

Step 2: Conversion of methyl levulinate to 2-butanone.

Step 3: 2-Butanone hydrogenation for biobutanol production.

A preliminary flow diagram of reagents and products envisioned for the 2-butanol production is presented in Fig. 2.

In the first step of the suggested pathway for the production of 2-butanol (Fig. 2), the biomass, the solvent and the catalyst are mixed and introduced into the reactor 01, which lead to convert the most part of the biomass into levulinates. At the end of the reaction, the

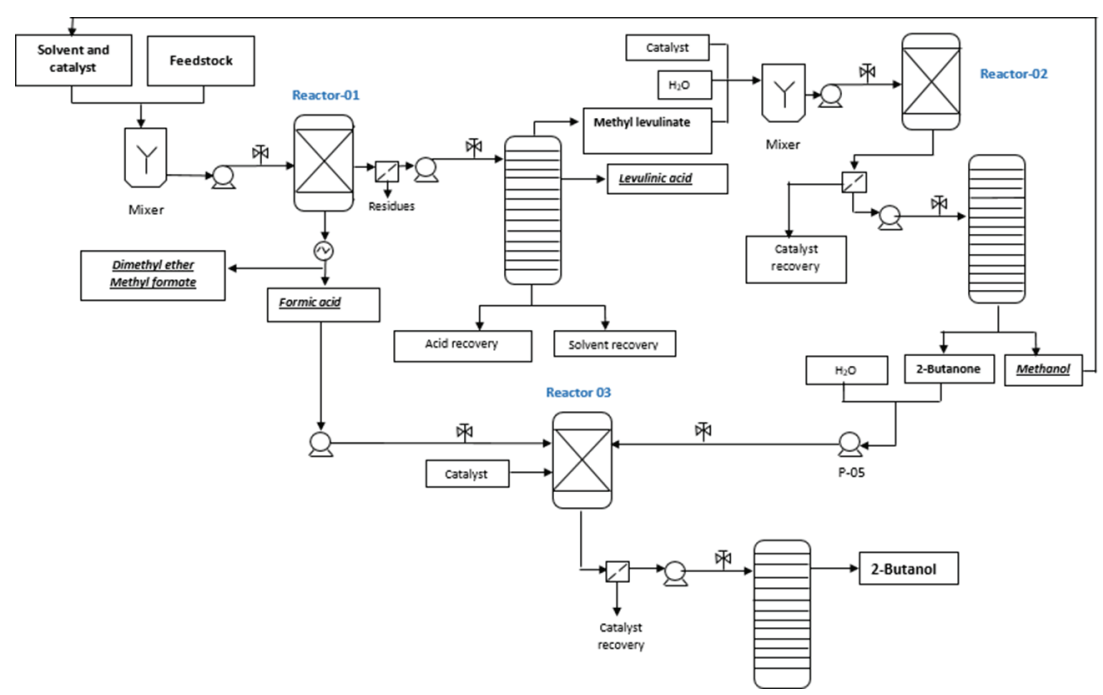

Figure 2: Suggested pathway for the production of 2-butanol from lignocellulosic biomass using the three-step process presented in this work. 
levulinates are separated from the byproducts (which consist of humins, formic acid, ethers and esters formate), the catalyst and the solvent by filtration and distillation. The second reactor is fed with the levulinates purified in the first stage. This stage represents a challenge due to the low 2-butanone yield obtained in the preliminary results. The use of different techniques of decarboxylation is been improving such as the use of catalysts or the pyrolysis of levulinates. At the end of the reaction, 2-butanone is purified and injected into the third reactor. The reaction is carry out with heterogeneous catalysts of $\mathrm{Ru} / \mathrm{C}$ or $\mathrm{Pd} / \mathrm{C}$ at moderate temperatures $\left(50-100^{\circ} \mathrm{C}\right)$ with two different solvents (water and ethanol). The first opportunity considered for biobutanol process is related to the possibility to recover the formic acid produce in the alcoholysis of lignocellulosic biomass. Formic acid can be used as hydrogen donor in the hydrogenation of 2-butanone. The second opportunity of the process is the possibility of solvents and catalysts recovery, which means the reduction of production process and less environmental problems associated to the use of toxic chemicals.

\section{LITTERATURE REVIEW}

Before carrying out a continuous process leading to butanol production, it is necessary to control the parameters linked to each step of the process, and how they interact with each other in order to optimize the yields of products and by-products. Thus, the process of each stage for the production of biobutanol (at laboratory scale) is explained below.

\subsection{Levulinates production from lignocellulosic biomass}

Levulinic acid is a fatty acid featuring both ketone and carboxylic acid functional group as well as being often presented as a high value-added molecule [12]. The esters of the latter have also shown many potential applications in the field of flavors and in the energy industry. As an example, these compounds have been tested as additives for gasoline and diesel in light of their high lubrication effect as well as lower toxicity, flashpoint stability and better flow properties under cold conditions [1]. Since levulinate esters could be produced from lignocellulosic biomass, they could be provided in large volumes while being renewable and potentially economical [2].

The two functional groups of levulinic acid and its esters allows different opportunities for these molecules to be used in different organic chemistry reactions such as condensation and addition both at laboratory as well as potentially at industrial scale.

Alkyl levulinate are mostly produced from catalyzed alcoholysis of carbohydrates, cellulose or lignocellulosic biomass. When it comes to catalyst, many options have been considered both on the heterogeneous (sulfated metal oxides, heteropolyacids, etc.) and homogeneous $\left(\mathrm{HCl}, \mathrm{H}_{2} \mathrm{SO}_{4}\right.$, etc.) catalyst side in both case operated in an alcohol media [13, 13-20]. This route only involves one-step, having the advantage of being technically simple while reducing effluents and providing products that can easily be purified by distillation [21].

Peng et al. [15] investigated the synthesis of methyl levulinate from glucose in acidified $\left(\mathrm{H}_{2} \mathrm{SO}_{4}\right)$ solution of methanol. Using $0.01 \mathrm{~mol} / \mathrm{L}$ of $\mathrm{H}_{2} \mathrm{SO}_{4}$ and $0.3 \mathrm{~mol} / \mathrm{L}$ of glucose at $200^{\circ} \mathrm{C}$ for 4 hours the highest yield of methyl levulinate reported in this work was $50 \mathrm{wt} \%$. Mineral acids have also been tested on cellulose, bringing such technology one-step closer to the direct use of lignocellulosic biomass. For example, Li, H. et al. 2013 [3] synthesized methyl levulinate with microcrystalline cellulose (particle size - $100 \mu \mathrm{m}$ ), methanol and sulfuric acid (at low concentration $\leq 0.01 \mathrm{~mol} / \mathrm{L}$ ) and using temperatures ranging from 180 to $200^{\circ} \mathrm{C}$. The highest yield of methyl levulinates $(50 \%)$ was obtained at $210^{\circ} \mathrm{C}$ using concentrations of cellulose and sulfuric acid of $20 \mathrm{~g} / \mathrm{L}$ and $0.01 \mathrm{~mol} / \mathrm{L}$ respectively while stirring at $400 \mathrm{rpm}$. 
Also, Wu et al. [22] converted microcrystalline cellulose to methyl levulinate at a $55 \mathrm{wt} \%$ yield using $20 \mathrm{~g} / \mathrm{L}$ of cellulose and $0.02 \mathrm{~mol} / \mathrm{L}$ of $\mathrm{H}_{2} \mathrm{SO}_{4}$, in $10 \mathrm{ml}$ of methanol at $190^{\circ} \mathrm{C}$ for 5 hours. Despite a certain availability of reports on the production of levulinates from cellulose or carbohydrates both using homogeneous or heterogeneous acids, fewer studies focused on the utilization of raw residual forest or agricultural biomass which would surely be beneficial to speed up industrial implementation.

\subsection{Conversion of levulinates to 2-butanone}

The second step envisioned in this process would lead to the production of biobutanol and involved the decarboxylation of levulinates to 2-butanone. In industry, the latter can be produced from a mixture of methyl formate, ethylene and carbon monoxide using a rhodium catalyst as well as an ionic iodide promoter [4]. 2-Butanone is generally used as a solvent for organic synthesis. The compound can be converted by the Baeyer-Villiger oxidation to ethyl acetate then further reduced to ethanol [5]. In this work, the decarboxylation of both levulinic acid and methyl levulinate was performed using pyrolysis. The decarboxylation step allowing the conversion of levulinates to butanone may be one of the key steps in converting biomass to butanol through the pathway suggested in this work.

Pyrolysis of carboxylic acid can lead to decarboxylation which involves removal of $\mathrm{CO}_{2}$ and, in the case of levulinic acids or esters, the formation of a ketone. The latter are generally relatively stable under moderate temperatures, and if a carboxyl group is bonded to the same molecule, the decarboxylation process generally show better kinetics as compared to the ketone decomposition. As example of partially oxidized acids, acetoacetic acid (3-oxobutanoic acid) is not very stable and decomposes to $\mathrm{CO}_{2}$ and acetone below $100^{\circ} \mathrm{C}$ [23]. $\gamma$-ketonic acids and $\delta$-ketonic acids such as levulinic acid behave differently from $\alpha$ and $\beta$ keto acids. Acids of this type are stable and can be distilled under vacuum. In addition, the keto-enol equilibrium of these compounds allows them to occur under two different and stable configurations [12].

The enol form allows the production of lactones since the ketone functional group is converted to an enol group by removing water in the early stages of pyrolysis (as shown in the Fig. 3) allowing the compound to react with the carboxylic acid function to generate the lactone structure (Fig. 4).

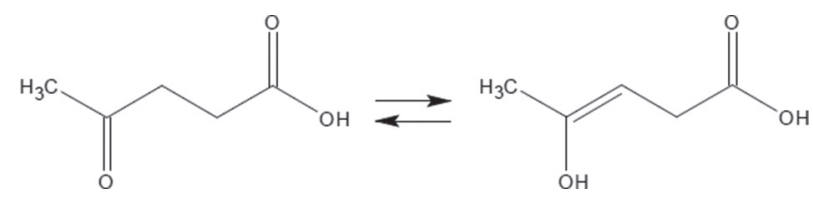

Figure 3: Keto-enol equilibrium in the pyrolysis of levulinic acid.
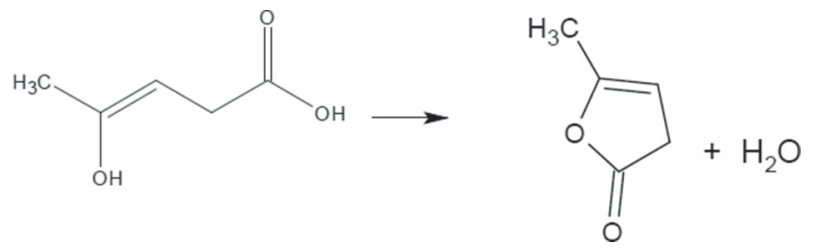

Figure 4: Levulinic acid decomposition by pyrolysis to produce angelica lactone. 
However, according to the preliminary results of the pyrolytic decarboxylation of levulinates, it is possible to decarboxylate the $\gamma$-ketonic acids into ketones but to date its reaction mechanism remains unknown.

\subsection{2-Butanone hydrogenation for biobutanol production}

Hydrogenation of 2-butanone to 2-butanol is a reaction that has attracted attention in recent years. One approach considered for the reduction of 2-butanone to 2-butanol could involve a catalytic hydrogen transfer reaction using the formic acid obtained in levulinates production reaction (formic acid is produced in equimolar ratio with levulinic acid from the conversion of C6 carbohydrates).

Bifunctional molecular catalysts based on ruthenium, palladium, rhodium and iridium complexes are used for the hydrogenation of ketones. The hydrogen transfer mechanism occurs through a complex in which the donor and the acceptor are bonded to the metal. The substrate is then activated toward the nucleophilic attack of the hydride and the metal acts as a template providing to the reactants the suitable orientation to allow the hydride transfer.

In the late 1970s, Williams and colleagues successfully used $\mathrm{Pd} / \mathrm{C}$ as heterogeneous catalysts for the decomposition of formic acid (to hydrogen and carbon dioxide) at room temperature [24]. According to Sasson et al. [25] using a metal salt (such as potassium formate), the only by-product that is generated during this reaction is potassium bicarbonate. In the absence of added salts, a certain amount of formate will be present due to the dissociation equilibrium of the acid, which then binds to the catalyst to induce the catalytic cycle. High formates concentrations may activate a greater proportion of the total amount of metal, while some species may remain inactive at lower concentrations.

Wan et al. [8] studied the effect of the solvent for a low-temperature hydrogenation of 2-butanone, 2-pentanone and phenol using a $\mathrm{Ru} / \mathrm{C}$ catalyst. They studied water, $\mathrm{C} 1-\mathrm{C} 4$ primary alcohols, polar solvents ( $\gamma$-butyrolactone, acetonitrile and tetrahydrofuran) and apolar solvents such as cyclohexane and n-heptane. They also found that for the hydrogenation of 2-butanone, $\mathrm{Ru} / \mathrm{C}$ catalyst has the highest hydrogenation activity in water reaching a $70 \%$ conversion.

In light of the observations that were made in open literature, the effects of solvent, temperature, reaction time as well as the presence of salts will be evaluated here using two different catalysts $(\mathrm{Ru} / \mathrm{C}$ and $\mathrm{Pd} / \mathrm{C})$ in order to obtain high yields of 2-butanol.

\section{METHODOLOGY}

\subsection{Levulinates production from lignocellulosic biomass}

Initially, the conversion of various raw materials (alpha-cellulose and biomasses) to methyl levulinate was evaluated using sulfuric acid as a catalyst in a methanol medium. Some additional experiments were made using ethanol as a solvent to compare the two solvents. All experiments were carried out in a cylindrical stainless steel $(316 \mathrm{~L})$ pressurized reactor with a total volume of $300 \mathrm{ml}$ acquired from PARR Instrument Company, USA. A $200 \mathrm{ml}$ monel sleeve was introduced inside the reactor to reduce corrosion. $\alpha$-cellulose and different lignocellulosic biomass were mixed with methanol and sulfuric acid in the reactor to reach a total reaction volume of $100 \mathrm{ml}$. The reaction were performed in the $180-200^{\circ} \mathrm{C}$ temperature range, biomass content range of $2.5 \%-12 \mathrm{wt} \%$, acid concentration varying from 0.04 to 0.24 $\mathrm{mol} / \mathrm{L}$, agitation $500 \mathrm{rpm}$ and reaction time ranging from $0.5 \mathrm{~h}$ to $7 \mathrm{~h}$. A type $\mathrm{G}$ thermocouple 
was used to control the temperature of the mixture. The concentration of levulinates was determined using a HPLC system (Agilent 1100 Series).

The experimental approach was analysed with a central composite design (CCD) using the response surface methodology (RSM) where two dependent responses (ML yield, LA yield) were studied to determine the optimum combination of the factors (acid concentration $(\mathrm{mol} / \mathrm{L})$, reaction time $(\mathrm{h})$, cellulose content $(\mathrm{wt} \%)$ and temperature $\left.\left({ }^{\circ} \mathrm{C}\right)\right)$.

\subsection{Conversion of levulinates to 2-butanone}

The conversion of levulinates to 2-butanone was carried out in an Inconel 718 (2.4668) HP/HT 3030000 pressurized reactor with a total volume of $0.270 \mathrm{~L}$ from Top Industrie S.A.S., France, RAPSODEE Center, Albi, France. A quantity of levulinates was introduced into the reactor, which was then heated to the desired temperature that was monitored using a type $\mathrm{K}$ thermocouple. The reactions were carried out in the temperature range varying from $335^{\circ} \mathrm{C}$ to $485^{\circ} \mathrm{C}$ for reaction time ranging of 0.5 to $6 \mathrm{hrs}$. At the end of the reaction, the reactor was cooled by a stream of compressed air in a vortex. Then, the gas was recovered and analyzed to determine the percentage of products by micro-GC (Agilent $3000 \mu \mathrm{GC}$ ). The sample was filtered to recover insoluble residues. The liquid phase was recovered and analyzed using a gas chromatograph mass spectrometer GCMS-TQ 8030 Shimadzu (Tokyo, Japon).

The experimental approach for the 2-butanone conversion was analysed with a Doehlert design (CCD) using the response surface methodology (RSM) where one dependent response (2-butanone yield) was studied to determine the optimum combination of the factors (reaction time (h) and temperature $\left.\left({ }^{\circ} \mathrm{C}\right)\right)$.

\subsection{2-Butanone hydrogenation for biobutanol production}

Preliminary tests for the hydrogenation of 2-butanone to 2-butanol were carried out. The conversion of 2-butanone to 2-butanol was evaluated using $5 \% \mathrm{Ru} / \mathrm{C}$ and $5 \% \mathrm{Pd} / \mathrm{C}$ in two solvents (water and ethanol). All experiments were performed in a cylindrical (316 L) cylindrical stainless steel pressurized reactor with a total volume of $300 \mathrm{ml}$ from PARR Instrument Company, USA. 2-Butanone, $5 \% \mathrm{Ru} / \mathrm{C}, 5 \% \mathrm{Pd} / \mathrm{C}$ and/or formic acid were mixed with the solvent for a total reaction volume of $100 \mathrm{ml}$. The reactions were carried out in the temperature range of $65^{\circ} \mathrm{C}$ to $200^{\circ} \mathrm{C}$ and a reaction time range of 0.5 to 3 hours. Once the reaction time reached, the reactor was removed from the mantle and placed in a cold water bath to quench the reaction. The concentration of 2-butanol and 2-butanone yield is determined using a HPLC system (Agilent 1100 Series). The mixture was vacuum filtered to separate the catalyst using a $1.5 \mu \mathrm{m}$ microfiber glass filter (VWR International, UK). The catalyst was dried at $105^{\circ} \mathrm{C}$ for 24 hours and was weighted.

\section{RESULTS AND DISCUSSION}

\subsection{Levulinates production results}

The response surface plots of the RSM as function of two variables are shown in Figs. 5 and 6. $3 \mathrm{D}$ response surface plots are helpful to evaluate the interaction of the factors and to establish the response values and operating conditions as required [13, 26]. As shown in Fig. 5a, as the cellulose content increased, at lower temperature was observed a decrease in the yield of methyl levulinate. It suggests that increasing the cellulose content at low temperature decrease 


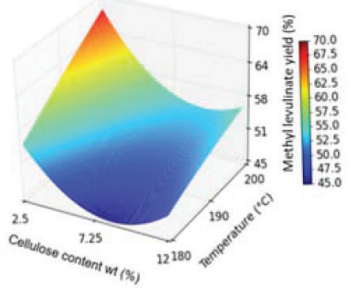

a)

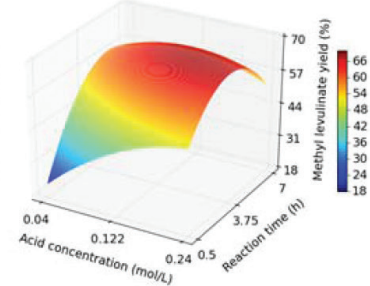

b)

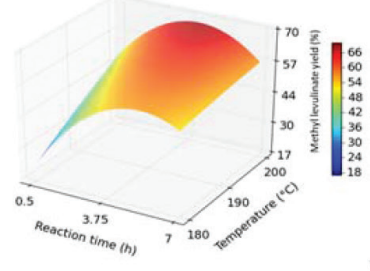

c)

Figure 5: 3D response surface plots of methyl levulinate yield versus cellulose content and temperature (a); acid concentration and reaction time (b) and reaction time and temperature (c) obtained from the acid catalyzed treatment of cellulose in methanol.

the mass transfer between the cellulose and the catalyst affecting the levulinates yield. The interaction between reaction time and acid concentration in Fig. 5b showed that methyl levulinate yields increased with acid concentration and reaction time until a maximum value was reached (acid concentration of $0.1785 \mathrm{~mol} / \mathrm{L}$ and reaction time of $4 \mathrm{~h}$ ). It reflects the strength of the acid sites of sulfuric acid for the synthesis of methyl levulinate. Once the optimum acid concentration value was reached $(0.1785 \mathrm{~mol} / \mathrm{L})$, the methyl levulinate yield decreased due to the degradation of the products, increasing the humins (insoluble component of soil organic matter) production. As shown in Fig. 5c, at lower temperature $\left(180^{\circ} \mathrm{C}\right)$ methyl levulinate yields increased slowly with regards to reaction time. The same behavior was reported by Peng et al. [15] for the conversion of glucose using sulfuric acid as catalyst. The temperature and reaction time played a positive role in the methyl levulinate yield until a maximum temperature $\left(200^{\circ} \mathrm{C}\right)$ and maximum reaction time $(4 \mathrm{~h})$ were reached. At higher temperature atoms give up or receive electrons more easily, increasing the chemical reaction rate [27]. Longer reaction time increase the methyl levulinate yield due to the transformation of the polymer chains of cellulose into low molecular weight fragments, which were further converted into methyl levulinate [27].

Afterwards, to reach the maximum conditions of temperature and reaction time $\left(200^{\circ} \mathrm{C}\right.$ at 4 hours), the methyl levulinate yield decreased due to its potential degradation, increasing the percentage of residues and corrosion into the reactor.

The presence of levulinic acid is due to the severity (high temperature and long reaction time) in the alcoholysis of $\alpha$-cellulose. It means that at high reaction conditions water molecules are produced from dehydration of cellulose and it leads to the levulinic acid formation. Figure 6a shows that increasing the temperature and reaction time led to an increase of the levulinic acid yield.

As shown in Fig. 6b, the yield of levulinic acid increased with an increase in acid concentration, which was also reported by Ya'aini et al. [28].

Based on the study of central composite design and the response surface methodology, the optimum conditions to reach the maximum levulinates yield were predicted, which was based on the variables in the range of experimental design using desirability function. The optimal conditions were acid concentration: $0.1796 \mathrm{~mol} / \mathrm{L}$, cellulose content: $2.5 \mathrm{wt} \%$, reaction time: $4 \mathrm{~h}$ at $200{ }^{\circ} \mathrm{C}$. The mean values for methyl levulinate and levulinic acid yield were $62.0 \mathrm{wt} \% \pm 0.3 \mathrm{wt} \%, 15.95 \mathrm{wt} \% \pm 2.2 \mathrm{wt} \%$. These results can be compared with the experiments found in the related literature. Wu et al. [22] obtained a $55 \mathrm{wt} \%$ yield of methyl levulinate using $20 \mathrm{~g} / \mathrm{L}$ of cellulose with a cellulose/catalyst ratio between 7 and 20 in $10 \mathrm{~mL}$ of methanol under almost critical conditions, $190^{\circ} \mathrm{C}$ for $5 \mathrm{~h}$. 


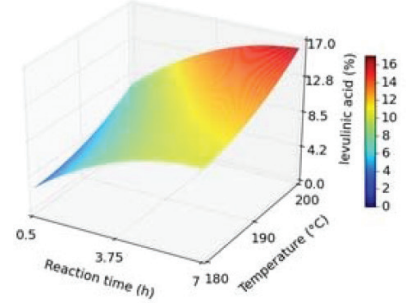

(a)

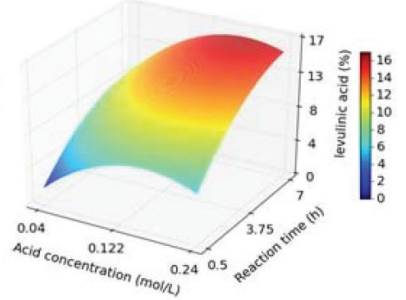

(b)

Figure 6: 3D response surface plots of levulinic acid yield versus reaction time and temperature (a) and acid concentration and reaction time (b) obtained from alcoholysis of cellulose using $\mathrm{H}_{2} \mathrm{SO}_{4}$ as catalyst.

Peng et al. [15] investigated the synthesis of methyl levulinate from glucose catalyzed by extremely low sulfuric acid $(\leq 0.01 \mathrm{~mol} / \mathrm{L})$. The experiments were carried out at temperatures between $160^{\circ} \mathrm{C}-200^{\circ} \mathrm{C}$ and the maximum yield of methyl levulinate obtained was $50 \mathrm{wt} \%$.

In order to validate the model, three different types of residual biomass were used (residual poplar wood, sorghum bagasse and softwood bark). The comparison was done under optimal conditions in the experimental design. According to the wet analysis, the cellulose for each biomass was $29 \mathrm{wt} \%, 30 \mathrm{wt} \%$ and $32 \mathrm{wt} \%$ for poplar, sorghum and barks respectively. The results for the predicted and real values for the levulinates yield produced with the different biomass are shown in the Table 2 .

The total levulinates values were $78 \mathrm{wt} \%, 72.5 \mathrm{wt} \%, 83 \mathrm{wt} \%$ and $73 \mathrm{wt} \%$ using $\alpha$-cellulose, poplar, sorghum and barks, respectively. The maximum methyl levulinate yield obtained was $68 \mathrm{wt} \%$ (from sorghum), together with a levulinic acid yield of $14.85 \mathrm{wt} \%$. The residues production for each biomass was $11.2 \mathrm{wt} \%, 30.8 \mathrm{wt} \%, 31.0 \mathrm{wt} \%$ and $42.1 \mathrm{wt} \%$ for $\alpha$-cellulose, poplar, sorghum and bark, respectively. The levulinates yields depended closely on the composition of the cellulosic raw material [13, 29].

\subsection{Levulinates decarboxylation preliminary results}

The pyrolysis of levulinates under the conditions tested produced gaseous products. Molecules as $\mathrm{CO}_{2}, \mathrm{CO}$, methane $\left(\mathrm{CH}_{4}\right)$, ethane $\left(\mathrm{C}_{2} \mathrm{H}_{6}\right)$, Propane $\left(\mathrm{C}_{3} \mathrm{H}_{8}\right)$, alkanes and alkenes were observed. Carbon dioxide and carbon monoxide were produced through decarboxylation and decarboxylation of levulinates.

Table 2: Levulinate results obtained from different biomasses using the optimal conditions. acid concentration: $0.1796 \mathrm{~mol} / \mathrm{L}$, cellulose content: $2.5 \mathrm{wt} \%$., reaction time: $4 \mathrm{~h}$ at $200^{\circ} \mathrm{C}$. (Yield of products (\%) based in cellulose content).

\begin{tabular}{lcc}
\hline & Methyl levulinate yield & Levulinic acid yield \\
\hline$\alpha$-Cellulose & $62.0 \% \pm 0.3 \%$ & $16.6 \% \pm 2.2 \%$ \\
Residual poplar wood & $53.2 \% \pm 2.7 \%$ & $19.3 \% \pm 1.4 \%$ \\
Sorgho bagasse & $68.1 \% \pm 1.5 \%$ & $15.2 \% \pm 3.3 \%$ \\
Softwood bark & $55.7 \% \pm 3.1 \%$ & $18 \% \pm 2.6 \%$ \\
\hline
\end{tabular}



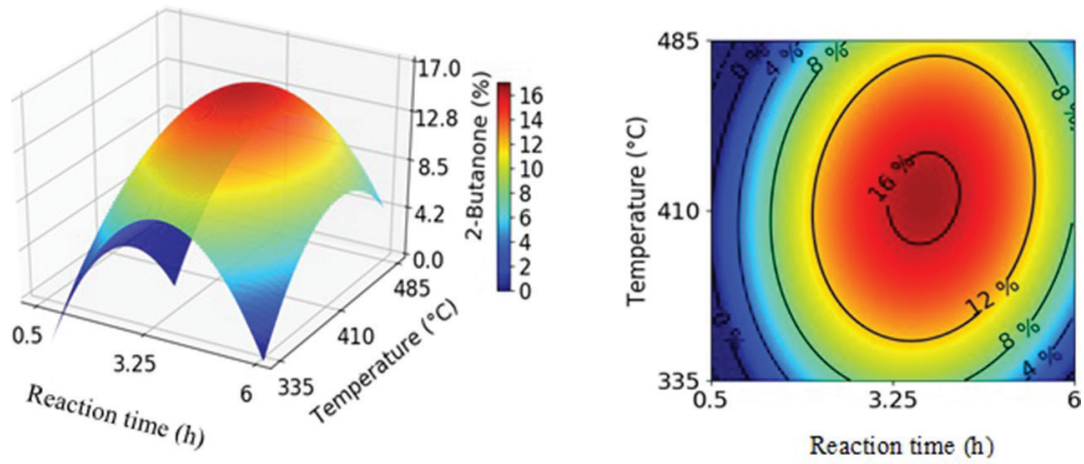

Figure 7: 3D response surface curvature and isoresponse curve of 2-butanone yield as a function of reaction time and temperature.

The study of 2-butanone production was carry out through 3D response surface plots and isoresponse curve of the response surface methodology of Doehlert design. The results of 2-butanone production as a function of reaction time and temperature for the levulinates decarboxylation are shown in Fig. 7.

At lower temperature $\left(<400^{\circ} \mathrm{C}\right), 2$-butanone yield increase slowly with regards to reaction time. The temperature and reaction time played a positive role in 2-butanone production until a maximum temperature $\left(410^{\circ} \mathrm{C}\right)$ and maximum reaction time $(3.5 \mathrm{~h})$ were reached. Increasing the temperature could contribute to the acceleration of the chemical reaction rate while enhancing the conversion efficiency [27].

On the other hand, preliminary results were performed using heterogeneous catalysts in hydrothermal conditions at moderated and high temperatures and it was not possible to detect the presence of 2-butanone by GC-MS.

\subsection{2-butanone hydrogenation into 2-butanol preliminary results}

First investigations started with the objective of finding which was the best catalyst for the hydrogenation of 2-butanone into to 2-butanol with different reaction conditions (Table 3). The catalysts were tested using hydrogen and formic acid as hydrogen donors. Best results were obtained using 5\%Ru/C. 2-butanol yield was $43 \%$ using $82 \mathrm{mmol}$ of 2-butanone,

Table 3: Reaction conditions for the hydrogenation of 2-butanone into 2-butanol using bifunctional catalysts $(5 \% \mathrm{Ru} / \mathrm{C}$ and $10 \% \mathrm{Pd} / \mathrm{C})$.

\begin{tabular}{ccccccc}
\hline Entry & Solvent & Catalyst & $\begin{array}{c}\text { Temperature } \\
\left({ }^{\circ} \mathbf{C}\right)\end{array}$ & Time (h) & $\begin{array}{c}\text { Hydrogen } \\
\text { source }\end{array}$ & $\begin{array}{c}\text { 2-Butanol } \\
\text { Yield (\%) }\end{array}$ \\
\hline 1 & Water & $5 \% \mathrm{Ru} / \mathrm{C}$ & 70 & 2 & $\mathrm{H}_{2}$ & 42.95 \\
2 & EtOH & $10 \% \mathrm{Pd} / \mathrm{C}$ & 50 & 1 & $\mathrm{H}_{2}$ & 2.35 \\
3 & $\mathrm{MeOH}$ & $10 \% \mathrm{Pd} / \mathrm{C}$ & 25 & 0.5 & $\mathrm{H}_{2}$ & 1.97 \\
4 & $\mathrm{EtOH}$ & $5 \% \mathrm{Ru} / \mathrm{C}$ & 70 & 3 & $\mathrm{CH}_{2} \mathrm{O}_{2} / \mathrm{KHCO}_{2}$ & 41.65 \\
5 & $\mathrm{EtOH}$ & $10 \% \mathrm{Pd} / \mathrm{C}$ & 70 & 2 & $\mathrm{KHCO}_{2}$ & 7.60 \\
6 & $\mathrm{EtOH}$ & $10 \% \mathrm{Pd} / \mathrm{C}$ & 70 & 1 & $\mathrm{NaHCO}_{2}$ & 18.08 \\
\hline
\end{tabular}


$5 \% \mathrm{Pd} / \mathrm{C}(0.125 \mathrm{~g})$, hydrogen $\left(\mathrm{H}_{2}\right)$ in aqueous solution $(100 \mathrm{~mL})$ at $70^{\circ} \mathrm{C}$ for $2 \mathrm{~h}$ (entry 1 , Table 3 ). The use of a base such as potassium formate with formic acid in a catalytic quantity was effective in a long reaction time using ethanol as solvent (entry 4, Table 3 ). In literature was found that the use of formate salts is an interesting alternative as a hydrogen source, which generates non-gaseous by-products that can be easily recovered [30].

To date, the reactions related to the hydrogenation of 2-butanone in 2-butanol are still being studied to determine which are the factors and the optimal conditions to obtain a higher yield of the product.

\section{CONCLUSIONS}

The global concern about environmental issues related to the use of fossil fuels have led the discovery of new industrial alternatives for energy production. Lignocellulosic biomass is a renewable, abundant and affordable resource that has attracted decades of attention for the production of second-generation biofuels. Cheap biomass could increase economic efficiency of new processes that are aimed to produce chemicals and fuels.

According to the preliminary results, the use of lignocellulosic biomass for 2-butanol production through three steps such as what was showed in this work could lead to a more technically and economically feasible approach to produce 2-butanol, a second-generation biofuel out of waste biomass. Although several methods of production of 2-butanol are possible, and were being demonstrated by many researchers, this work has contributed to determine a completely new 2-butanol production strategies from the lignocellulosic biomass that are still being studied.

\section{ACKNOWLEDGEMENTS}

The authors are grateful for the financial support to MITACS (Grant number ITO3931) and for the grant to the Natural Sciences and Engineering Research Council of Canada (NSERC, Grant number EGP 487206-15). Further acknowledgements to Sophie Beauchemin and the analytical laboratory from Biomass technology laboratory for their valuable support for analyzing all the samples included in this work. This study was funded by MITACS and the Natural Sciences and Engineering Research Council of Canada (NSERC).

\section{REFERENCES}

[1] Steinfeld, J.I., Energy futures and green chemistry: competing for carbon. Sustainability Science, 1(1), pp. 123-126, 2006. https://doi.org/10.1007/s11625-006-0004-7

[2] Bayraktar, H., Experimental and theoretical investigation of using gasoline-ethanol blends in spark-ignition engines. Renew Energy, 30(11), 1733-1747, 2005. https://doi. org/10.1016/j.renene.2005.01.006

[3] Anderson, J.E., DiCicco, D.M., Ginder, J.M., Kramer, U., Leone, T.G., Raney-Pablo, H.E. \& Wallington, T.J., High octane number ethanol-gasoline blends: Quantifying the potential benefits in the United States. Fuel, 97, pp. 585-594, 2012. https://doi.org/10.1016/j. fuel.2012.03.017

[4] Pereira, L.G., Dias, M.O.S., Mariano, A.P., Maciel Filho, R. \& Bonomi, A., Economic and environmental assessment of n-butanol production in an integrated first and second generation sugarcane biorefinery: Fermentative versus catalytic routes. Applied Energy, 160, pp. 120-31, 2015. https://doi.org/10.1016/j.apenergy.2015.09.063

[5] Ndou, A.S., Plint, N. \& Coville, N.J., Dimerisation of ethanol to butanol over solidbase catalysts. Applied Catalysis A: General, 251(2), pp. 337-345, 2003. https://doi. org/10.1016/s0926-860x(03)00363-6 
[6] Paul, B.J., Enhanced pyruvate to 2,3-butanediol conversion in lactic acid bacteria. US8455224B2, 2013.

[7] Canada, N.R., Current lumber, pulp and panel prices 2013. https://www.nrcan.gc.ca/ forests/industry/current-prices/13309 (accessed 5 February 2019).

[8] Dernotte, J., Mounaim-Rousselle, C., Halter, F. \& Seers, P., Evaluation of ButanolGasoline blends in a port fuel-injection, spark-ignition engine. Oil Gas Sci Technol-Rev L'Institut Fr Pétrole, 65(2), pp. 345-351, 2010. https://doi.org/10.2516/ogst/2009034

[9] Xu, W., Al-Shahrani, F.M., Bourane, A. \& Vogel, S.R., Process for the hydration of mixed butenes to produce mixed alcohols. EP2665697A2, 2013.

[10] Rakopoulos, D.C., Rakopoulos, C,D., Papagiannakis, R.G. \& Kyritsis, D.C., Combustion heat release analysis of ethanol or n-butanol diesel fuel blends in heavy-duty DI diesel engine. Fuel, 90(5), pp. 1855-1867, 2011. https://doi.org/10.1016/j.fuel.2010.12.003

[11] Rice, R.W., Sanyal, A.K., Elrod, A,C. \& Bata, R.M., Exhaust gas emissions of Butanol, Ethanol, and Methanol-Gasoline Blends. Journal of Engineering for Gas Turbines and Power, 113(3), pp. 377-381, 1991. https://doi.org/10.1115/1.2906241

[12] Timokhin, B.V., Baransky, V.A. \& Eliseeva, G.D., Levulinic acid in organic synthesis. Russian Chemical Reviews, 68, pp. 73-84, 1999. https://doi.org/10.1070/rc1999v068n01abeh000381

[13] Chang, C., Xu, G. \& Jiang, X., Production of ethyl levulinate by direct conversion of wheat straw in ethanol media. Bioresource Technology, 121, pp. 93-99, 2012. https:// doi.org/10.1016/j.biortech.2012.06.105

[14] Ding, D., Xi, J., Wang, J., Liu, X., Lu, G. \& Wang, Y., Production of methyl levulinate from cellulose: selectivity and mechanism study. Green Chemistry, 17(7), pp. 4037-4044, 2015. https://doi.org/10.1039/c5gc00440c

[15] Peng, L., Lin, L. \& Li, H., Extremely low sulfuric acid catalyst system for synthesis of methyl levulinate from glucose. Industrial Crops and Products, 40, pp. 136-144, 2012. https://doi.org/10.1016/j.indcrop.2012.03.007

[16] Peng, L., Lin, L., Li, H. \& Yang, Q., Conversion of carbohydrates biomass into levulinate esters using heterogeneous catalysts. Applied Energy, 88(12), pp. 4590-4596, 2011. https://doi.org/10.1016/j.apenergy.2011.05.049

[17] Rataboul, F. \& Essayem, N., Cellulose reactivity in supercritical methanol in the presence of solid acid catalysts: direct synthesis of methyl-levulinate. Industrial \& Engineering Chemistry Research, 50(2), pp. 799-805, 2011. https://doi.org/10.1021/ie101616e

[18] Zhang, J., Wu, S., Li, B. \& Zhang, H., Advances in the catalytic production of valuable levulinic acid derivatives. ChemCatChem, 4(9), pp. 1230-1237, 2012. https://doi. org/10.1002/cctc.201200113

[19] Le Van Mao, R., Zhao, Q., Dima, G. \& Petraccone, D., New process for the acidcatalyzed conversion of cellulosic biomass (AC3B) into alkyl levulinates and other esters using a unique one-pot system of reaction and product extraction. Catalysis Letters, 141, pp. 271-276, 2011. https://doi.org/10.1007/s10562-010-0493-y

[20] Mao, R.L.V., Catalytic conversion of ligno-cellulosic biomass into fuels and chemicals. WO2013127006A1, 2013.

[21] Garves, K., Acid catalyzed degradation of cellulose in alcohols. Journal of Wood Chemistry and Technology, 8(1), pp. 121-134, 1988. https://doi. org/10.1080/02773818808070674

[22] Wu, X., Fu, J. \& Lu, X., One-pot preparation of methyl levulinate from catalytic alcoholysis of cellulose in near-critical methanol. Carbohydrate Research, 358, pp. 37-39, 2012. https://doi.org/10.1016/j.carres.2012.07.002 
[23] Moldoveanu, S.C., Pyrolysis of Organic Molecules: Applications to Health and Environmental Issues. Elsevier, 2009.

[24] Williams, R., Crandall, R.S. \& Bloom, A., Use of carbon dioxide in energy storage. Applied Physics Letters, 33, pp. 381-383, 1978. https://doi.org/10.1063/1.90403

[25] Wiener, H., Blum, J., Feilchenfeld, H., Sasson, Y. \& Zalmanov, N., The heterogeneous catalytic hydrogenation of bicarbonate to formate in aqueous solutions. Journal of Catalysis, 110(1), pp. 184-190, 1988. https://doi.org/10.1016/0021-9517(88)90308-9

[26] Jeya, M., Kalyani, D., Dhiman, S.S., Kim, H., Woo, S., Kim, D. \& Lee, J., Saccharification of woody biomass using glycoside hydrolases from Stereum hirsutum. Bioresource Technology, 117, pp. 310-316, 2012. https://doi.org/10.1016/j.biortech.2012.03.047

[27] Li, H., Peng, L., Lin, L., Chen, K. \& Zhang, H., Synthesis, isolation and characterization of methyl levulinate from cellulose catalyzed by extremely low concentration acid. Journal of Energy Chemistry, 22(6), pp. 895-901, 2013. https://doi.org/10.1016/s20954956(14)60269-2

[28] Ya'aini, N., Amin, NAS. \& Asmadi, M., Optimization of levulinic acid from lignocellulosic biomass using a new hybrid catalyst. Bioresource Technology, 116, pp. 58-65, 2012. https://doi.org/10.1016/j.biortech.2012.03.097

[29] Olson, E.S., Kjelden, M.R., Schlag, A.J. \& Sharma, R.K., Levulinate esters from biomass wastes. American Chemical Society, pp. 51-63, 2001. https://doi.org/10.1021/ bk-2001-0784.ch005

[30] Prasad, K., Jiang, X., Slade, J.S., Clemens, J., Repič, O. \& Blacklock, T.J., New trends in Palladium-catalyzed transfer hydrogenations using Formic Acid. Advanced Synthesis \& Catalysis, 347(14), pp. 1769-1773, 2005. doi:10.1002/adsc.200505132 